\title{
Cultura e comunicação como direitos humanos: aproximações diante da nova onda neoliberal
}

Culture and Communication as human rights: approaches to the new neoliberal wave

\author{
Adilson Vaz Cabral Filho* \\ Eula Dantas Taveira Cabral ${ }^{* *}$
}

\section{RESUMO}

Diante da nova onda neoliberal posta em marcha em todo mundo e, particularmente na América Latina, busca-se investigar a afirmação de políticas públicas que aproximem a Cultura e a Comunicação como direitos humanos. Com base nas pesquisas bibliográfica e documental, são abordadas propostas de formulação e implementação de políticas culturais e de comunicação no continente, proporcionando uma compreensão ampla e integrada em relação a segmentos sociais distintos, evidenciando possíveis articulações para a construção de políticas democráticas alternativas.

Palavras-chave: Direito Humano à Comunicação; Diversidade Cultural; Políticas de Comunicação.

\begin{abstract}
Facing the new neoliberal wave set in motion around the world and, particularly in Latin America, we seek to investigate the affirmation of public policies that place Culture and Communication as human rights. Based on bibliographic and documental research, this article brings proposals for formulation and implementation of cultural and communication policies on the continent, providing a broad and integrated understanding among distinct social segments, highlighting possible articulations for building alternative democratic policies.

Keywords: Human Right to Communication; Cultural Diversity;Communication Policies.
\end{abstract}

\section{INTRODUÇÃO}

A nova onda neoliberal posta em marcha em todo mundo e, particularmente, na América Latina proporcionou o desmoronamento de quase duas décadas de governos progressistas em favor de uma agenda que articula elementos liberais e

\footnotetext{
* Adilson Vaz Cabral Filho - Doutor em Comunicação Social pela Universidade Metodista de São (Umesp) com Pós-doutorado em Comunicação pela Universidade Carlos III de Madrid. Universidade Federal Fluminense (UFF) no Curso de Comunicação Social e no Programa de Pós-graduação em Mídia e Cotidiano (PPGMC). Telefone (21) 98125-9388. Email: acabral@comunicacao.pro.br.

** Eula Dantas Taveira Cabral - Doutora em Comunicação Social pela Universidade Metodista de São (Umesp) com Pós-doutorado em Comunicação pela Universidade do Estado do Rio de Janeiro (UERJ). Programa de Pós-graduação em Memória e Acervos (PPGMA) da Fundação Casa de Rui Barbosa (FCRB). Telefone (21) 98125-9387. Email: eulacabral@gmail.com.
} 
conservadores na economia e na cultura. Apesar da ampla derrota nos processos eleitorais recentes, permanecem intrinsecamente vinculados às forças de esquerda valores como a minimização da desigualdade de renda, fomentando oportunidades na economia; o fortalecimento da soberania dos países, reforçando laços entre povos comuns; a maximização do acesso a espaços de formação e atuação profissional, além da defesa inalienável dos direitos humanos fundamentais, entre eles a comunicação e a cultura.

Frente à nova onda neoliberal que vem desmontando um projeto de Estado alicerçado na defesa dos direitos humanos, temas essenciais como educação, saúde, segurança e moradia voltam a ser compreendidos como prioritários por parte de organizações e movimentos sociais, em detrimento da importância que a Comunicação e a Cultura chegaram a exercer na forma de políticas públicas por parte de governos progressistas no continente.

Diante desse cenário, propõe-se nessa investigação recontextualizar o enfrentamento da demanda pelas articulações entre Cultura e Comunicação, com base em pesquisa bibliográfica a partir de autores de referência que tratam da relação dessas áreas com a democracia e os direitos humanos, além de pesquisa documental, voltada para a implementação de políticas públicas para o setor. Busca caracterizar a abrangência político-econômica e sócio-cultural dessa nova onda neoliberal, em especial nos países da América Latina. Em seguida, identifica conquistas e limites relacionados à Cultura, à Comunicação e a suas interlocuções e, por fim, apresenta perspectivas de formulação e implementação de políticas públicas comprometidas com a Comunicação e a Cultura como direito humano, articuladas com a afirmação de outros direitos.

\section{ENFRENTAMENTO A UMA NOVA ORDEM NEOCONSERVADORA}

Mais que se restringir apenas ao Brasil ou a América Latina, a onda neoconservadora em curso está despertando lideranças e mobilizando redes em todo o mundo a partir de um ideário comum, não apenas restrito ao neoliberalismo econômico ou ao conservadorismo de costumes. A afirmação do sentimento patriótico em detrimento ao de nação, consolidado a partir do final da $2^{a}$ Guerra Mundial, tendo a aprovação da Declaração Universal dos Direitos Humanos (ONU, 1948) como maior referência, articula um discurso antiglobalista, cuja manifestação já se fez presente nos discursos de governantes do Brasil, Jair Bolsonaro, e dos EUA, Donald Trump, durante a $73^{\mathrm{a}}$ Assembleia Geral da ONU, realizada em 2019, em Nova lorque (EUA).

Ao mesmo tempo em que buscam influenciar e intervir em políticas no âmbito das Nações Unidas, governantes e participantes de partidos e organizações se mobilizam em torno da Cúpula de Demografia, realizada em Budapeste, em 2019, a partir da qual está sendo proposta a ação de um grupo de países autonomeados "amigos da família", compreendida em seu modelo tradicional, visando o aumento da população europeia cristã. Outra articulação de cunho patriótico é a CPAC - Conferência de Ação Política Conservadora, implementada nos EUA e importada pela nova direita brasileira, cuja agenda busca articular e reforçar um amplo espectro conservador em várias frentes de atuação. E na América Latina, a nova articulação da ProSul, formada originalmente por 14 países latino-americanos, mobilizados pela afirmação de uma agenda mais focada em interesses bilaterais que multilaterais de formação de blocos.

Desse modo, a América Latina aparece como espaço especial no tocante a uma reação de caráter global, que compreende, no avanço de uma agenda pautada na 
afirmação de direitos humanos fundamentais que variam em cada país, uma ameaça a ser desconstruída e inviabilizada em seu potencial de transformação social.

Portanto, longe de ser menos preocupante o foco numa determinada região, esse deslocamento conservador é um fenômeno mundial preocupante, articulado com o desinteresse crescente das populações e, em especial, dos jovens, pela democracia como fundamento das políticas públicas. Para Mounk (2018, p. 104), a democracia só poderia ser colocada como única opção para as populações a partir de três elementos:

\begin{abstract}
a maioria dos cidadãos teria de ser fortemente comprometida com a democracia liberal; a maioria dos cidadãos teria de rejeitar alternativas autoritárias à democracia e os partidos políticos e movimentos com poder real teriam de concordar com a importância das regras e normas democráticas básicas.
\end{abstract}

Mas isso, segundo o autor, não está acontecendo. Em várias sociedades ocidentais, as motivações compreendem uma reação aos significativos avanços relacionados à afirmação de direitos humanos fundamentais, por um lado, e por outro, pela insatisfação diante da ineficiência de políticas públicas sociais motivada, entre outros fatores, pela crise do trabalho acelerada pela revolução tecnológica. Apesar da desmobilização para assuntos relacionados à política, populações em diversos países pesquisados por Mounk (2018) vêm se dispondo a abrir mão de sistemas de governo democráticos em prol de garantias de empregabilidade.

O descaso com processos característicos da democracia representativa levou à adoção de um lema significativo nas eleições do Parlamento Europeu em 2019: "agora é o voto". Se obtiveram êxito no processo eleitoral, convivem também com avanços ameaçadores da ultradireita, articulados por uma plataforma comum, a partir de bases que tomam as mídias sociais como partida, mas não se restringem a elas: compreendem a manipulação de grandes dados (data mining / big data) para a conformação de algoritmos orientados a afirmar determinados conteúdos e palavraschave destinados a públicos específicos (MOSCO, 2017). O controle dos procedimentos dessas plataformas, articulado à conformação tradicional de redes e grupos sociais em distintos contextos, permite formar blocos de poder que já vêm sendo compreendidos como de gramscianização da direita, pela assimilação de estratégias de construção de uma contra-hegemonia a partir de forças ultraconservadoras (FEBBRO, 2018).

Tema-chave de desmobilização de projetos de poder existentes a partir dessa malha de articulação sociotécnica, a corrupção como alvo não resulta no enquadramento de privilégios a determinados setores do serviço público nem à identificação de padrões comuns de captura regulatória a partir de determinados padrões que poderiam ser coletivamente estabelecidos. Além disso, a agenda mantenedora da exploração de riquezas e bens naturais, como o pré-sal e a região da Amazônia, reforça interesses de grupos dominantes que atuam fora do continente, reproduzindo lógicas imperialistas, nas quais os países latino-americanos se dispõem a assumir posturas subservientes. A sustentação de forças capazes de oferecer falsas promessas no campo político ou do Judiciário é insuflada pela mídia, que em maior ou menor grau não chegou a concretizar seu potencial democratizante, sendo que os conteúdos que produzem são disseminados em plataformas digitais que elencam temáticas, abordagens e origens em processos de reputação e legitimação alheios à maioria da população, a partir de interesses que estão longe de ser republicanos. 
Desse modo, não apenas as recorrentes guerras híbridas, como as inevitáveis fake news, promovem um desencontro de informações e mobilizam setores conservadores que se articulam pela afirmação e acolhida de discursos e narrativas assumidas como verdades. Mesmo com alguma reação, com conquistas em alguns países, e avanços em outros, deslocam o centro político para a direita, construindo variações conservadoras da mais branda a mais extrema.

Embora desanimador e desalentador, o cenário latino-americano oferece diversos desafios e oportunidades no âmbito da cultura e da comunicação. Para Caballero e Gravante (2018, p. 32) as "teorias sobre cultura e comunicação na América Latina relacionadas à miscegenação e a hibridização ajudam a compreender o complexo relacionamento entre a mídia digital e as ações coletivas". Assim, cabe entender tais articulações diante dos desafios que o tempo presente nos oferece.

\section{DEMOCRATIZAÇÃO DA COMUNICAÇÃO E DIVERSIDADE CULTURAL}

No Brasil, durante o governo Lula, havia uma grande expectativa da sociedade em relação à democratização da comunicação no país. Entretanto, a despeito da realização da I Conferência Nacional de Comunicação, realizada em 2009, os anos seguintes não concretizaram os anseios em relação ao setor. Os debates aconteceram de modo tímido e restrito, com pouca sinalização de avanços reais e sem levar em conta as propostas aprovadas na referida Conferência, feita com a participação de representantes de governo, empresas e da sociedade civil não comercial.

Já desde a realização do I Fórum Nacional de TVs Públicas, realizado em maio de 2007, em Brasília, foi criada a EBC - Empresa Brasil de Comunicação, pela Medida Provisória ${ }^{\circ} 398$, de 10 de outubro de 2007 (BRASIL, 2007) e regulamentada pela Lei 11652/2008 (BRASIL, 2008). Sua estrutura fundiu a Radiobrás com as emissoras da Fundação Roquete Pinto e sua gestão compreendeu um Conselho de Administração e uma Diretoria Executiva, além de um Conselho Fiscal e um Conselho Curador, todos designados e destituíveis pelo Presidente da Republica. Apesar de ter sido compreendida em torno de uma ampla mobilização, articulando governo e sociedade em prol da criação de um sistema público de comunicação, sua amarração estatal não apenas limitou a participação social ao longo de seus primeiros anos, como também resultou mais vulnerável, quando da mudança de turno no governo federal, já com Temer e, posteriormente, no governo Bolsonaro.

Se o processo que empossou Temer já abriu espaço para o desmonte para a frágil estrutura constituída ao longo dos governos Lula e Dilma, extinguindo o Conselho Curador da emissora, no governo Bolsonaro a ingerência vem sendo ainda maior, inviabilizando a proposta incipiente de comunicação pública em curso, fundindo-a com a NBR, canal de televisão responsável pela comunicação institucional do governo e tornando-a uma emissora eminentemente estatal. Para além do desmoronamento da comunicação pública e da afirmação de uma comunicação estatal orientada a uma política que promove uma ampla destruição de direitos em diversos setores sociais, o próprio jornalismo como prática profissional se vê ameaçado bem como cerceadas as práticas alternativas de comunicação por parte de movimentos e organizações sociais que atuam historicamente no combate à desinformação, bem como na promoção da cidadania e da participação popular.

A democratização da comunicação é uma histórica bandeira de luta dos movimentos sociais no Brasil. Preocupação de organizações sociais em suas atuações diárias, leva 
em consideração as necessidades da reformulação de políticas públicas, considera a diversidade de produtores capacitados e qualificados para acessar e exercer o controle sobre os meios de grande circulação, além de implementar meios de alcance local e comunitário.

A luta pela democratização da comunicação no Brasil é resultado de uma iniciativa que se vincula "aos esforços para uma reestruturação da sociedade brasileira, com o estabelecimento de garantias para o acesso a serviços públicos, ao trabalho e a condições de vida dignas para todos os brasileiros" (BASES..., 1994). De acordo com Murilo César Ramos (2000, p. 93), esta luta seria oriunda da mobilização de uma "opinião pública dotada do poder de tomar decisões e dar consequências a essas decisões, a partir, por exemplo, de conselhos populares e organizações produtivas em que predominem a propriedade cooperativa ou outras formas de autogestão".

Trata-se de um conceito apropriado pelas organizações da sociedade civil ligadas ao movimento pela democratização da comunicação no Brasil, transformando-o em bandeira de luta e propondo elementos que a constituiriam. É o caso do slogan do Fórum Nacional pela Democratização da Comunicação (FNDC), que traduz sua forma de atuação: "democratizar a comunicação para a democratização da sociedade", estabelecendo a necessidade de tornar a comunicação mais democrática como condição prévia à democratização da sociedade, cumprindo um duplo papel de ressaltar o papel potencializador da comunicação nas lutas específicas dos diversos movimentos sociais e as particularidades da comunicação como temática própria, dentro de um sistema restritivo e excludente, que inibe uma efetiva participação no seu processo de produção.

Outros autores ligam o conceito ao Direito à Comunicação. Cees Hamelink (in MELO e SATHLER, 2005, p. 144) mostra que, desde a introdução deste direito pela UNESCO, em 1994, "o direito a comunicar é percebido por seus protagonistas como mais fundamental do que o direito à informação, como atualmente disposto pelas leis internacionais". O redimensionamento do artigo 19, a partir dos diversos debates que se seguiram, proporcionou o surgimento da Plataforma para os Direitos da Comunicação, um agrupamento de ONGs formado em 1996, em Londres, que por sua vez, em 2001, fundou a Campanha CRIS, sigla que significa, em português, Direitos à Comunicação na Sociedade da Informação.

Pesquisas relacionadas à formulação e implementação das políticas públicas de comunicação nos países latino-americanos apresentam um cenário de melhor aproveitamento das oportunidades proporcionadas por governos progressistas na década de 2000. Em estudo pioneiro, Dênis de Moraes (2009, p.20) analisou a transformação então em curso pela sua capacidade de "superar a histórica letargia do Estado diante da avassaladora concentração dos setores de informação e entretenimento nas mãos de um reduzido número de megagrupos nacionais e transnacionais". Moreira (2013) enfoca avanços normativos aos meios comunitários proporcionados pelos governos progressistas latino-americanas, dando ênfase à Argentina, Brasil e Venezuela, como leis implementadas a partir de "uma complexa correlação de forças, em que a agência dos atores contra-hegemônicos é decisiva para a construção de novos caminhos". Já Sáez Baeza (2008) comparou a legislação e as práticas da Espanha com casos exemplares sobre a figura do acesso público individualizado dos Estados Unidos e a do acesso público coletivo, em torno da proposta bolivariana da Venezuela. 
Para Marcos Alberto Bitelli (2004, p.168), há "o interesse tão grande da sociedade e do Estado por ela organizado diante desses direitos (de informar e ser informado), pois somente uma pessoa humana 'consciente' poderá ter satisfeito o atendimento desse princípio fundamental”. Ou seja, a comunicação é um direito e um dever de todo(a)s.

Se, por um lado, democratizar a comunicação significa recobrar o que esta atividade tem de vital, ou seja, reivindicar a dimensão original de diálogo e horizontalidade da comunicação, a ideia de lutar pelo direito humano à comunicação está diretamente relacionada à mobilização tanto daqueles que buscam exercê-la mais diretamente na prática - ativistas e jornalistas, por exemplo, como expandindo esse direito àqueles que têm competência para tanto, ou seja, à sociedade como um todo.

A mobilização em prol da democratização da comunicação na América Latina vem demonstrando, portanto, que há muitos espaços a se conquistar por parte dos movimentos sociais, no tocante ao envolvimento pleno e não hierárquico das pessoas e organizações. Para John Holloway (2003, p. 50) "a existência do poder-fazer como poder-sobre significa que a imensa maioria dos fazedores são convertidos em objetos do fazer" e esse não é privilégio somente das relações capitalistas, mas também algo que os movimentos sociais necessitam enfrentar e superar.

No que tange à diversidade cultural, além das legislações nacionais e internacionais, são levadas em consideração análises sobre a comunicação, a mídia e a informação, articulando conceitos clássicos e críticos sobre cultura. Como observou José Augusto Lindgren-Alves (2018, p.188), "no âmbito dos direitos humanos, os direitos culturais são direitos dos indivíduos". Não é à toa que Marcela Carvalho (2018) chama a atenção para a importância da cultura como um direito dentro da Constituição da República Federativa do Brasil de 1988.

É preciso lutar pelos direitos culturais e entender como são as políticas culturais no Brasil e nos demais países da América Latina e o lugar da cultura, como vem sendo estudado desde a seminal obra de Canclini (1987) e por Lia Calabre (2013). Margarethe Steinberger (2009) investiga as representações interculturais na mídia. César Bolaño, Valério Brittos e Cida Golin (2010) analisam a diversidade cultural a partir da Economia da Arte da Cultura. Chris Barker (2003) trabalha a partir de identidades culturais.

Entendendo a comunicação e a cultura como direitos humanos, será possível verificar como a concentração pode interferir na sociedade (CABRAL, 2015a, 2019), como as pessoas poderão reagir e exigir que haja democratização na mídia brasileira. As mudanças tecnológicas e seus impactos na sociedade podem ser compreendidas a partir de estudos de Adilson Cabral (2015, 2019), que analisa a regulamentação democrática da radiodifusão comunitária na América Latina, o ativismo digital e a importância da TV digital no Brasil e sua apropriação pelas organizações e pelos grupos sociais; Michael Wolff (2015), que verifica a televisão como nova e atualizada plataforma diante da era digital; Luis Pereira Junior (2002), que mostra como a TV interfere no cotidiano do brasileiro; Laurindo Leal Filho (2006), que analisa o controle e a reação do telespectador brasileiro; Octavio Pieranti (2011), que estuda a atuação do Estado brasileiro diante das comunicações; dentre outros.

Como verificou Othon Jambeiro (2000, p.15), "o Estado continua com forte presença em todos os processos regulatórios da região, mas é crescente o poder dos conglomerados de mídia nacionais e internacionais na regulamentação, operação e programação do setor". Como entender por que o Estado não atua e evita a concentração midiática? Como ignorar o quadro atual? Pâmela Pinto (2017) mostra a 
influência dos políticos nos grupos de mídia brasileiros, mesmo sendo proibido na Constituição de 1988; Janaína Aires e Suzy dos Santos (2017) analisam a mídia brasileira a partir do conceito de coronelismo eletrônico. Pois, como observou Venício Lima (2012, p.34), "a democracia brasileira será a grande vencedora quando o debate sobre as concessões de rádio e TV conseguir romper o bloqueio da grande mídia e alcançar a maioria da população".

Faz-se de vital importância analisar o cenário atual, verificando como a mídia interfere na seleção de informações e opiniões e como consegue evitar que a articulação entre a democratização da comunicação e a diversidade cultural se torne real. "A opinião pública é induzida ao convencimento de que só tem relevância social aquilo que se expõe em telas e monitores" e "o que se manifesta à margem da grande mídia parece condenado ao esquecimento ou a uma repercussão de baixa densidade" (MORAES, 2016, p.115).

\section{EM ARTICULAÇÃO COM OUTROS DIREITOS}

Alguns países na América Latina, como Argentina, Bolívia, Equador, Uruguai e Venezuela, tiveram oportunidades para implementar políticas públicas democráticas na área da Comunicação e aproveitaram para consolidar práticas e processos culturais capazes de tecer uma ampla rede de iniciativas comunicacionais fortalecedoras de distintas culturas locais. Alinham não apenas direitos humanos nas áreas de Cultura e Comunicação, mas articulam distintas frentes em áreas fundamentais como Educação, Saúde, Moradia, Criança e Adolescência, entre outras, transpondo armadilhas supostamente aglutinadoras, mas efetivamente fragmentárias, como propostas de cunho identitário tópico, desvinculados a processos dotados de visão sistêmica capazes de compreender papéis mais que instrumentais para o desenvolvimento e a mudança social, afirmando a pluralidade e a diversidade em seus processos de gestão e produção, bem como reivindicando espaços a serem ocupados e afirmados que incorporem projetos de construção cidadã.

Assim se reforça uma base aglutinadora de iniciativas em áreas distintas, capazes de identificar bases comuns de articulação convergente e multiplataforma, propondo uma defesa inalienável dos direitos humanos, compreendendo, entre eles, o direito à Comunicação e à Cultura. Políticas complementares, mas que em muitos contextos caminham paralelas, processos comunicacionais e culturais são mutuamente dependentes: se a Cultura dá sentido à Comunicação, esgarçando seu potencial democrático e cidadão, a Comunicação por sua vez da abrangência e pertinência à Cultura, proporcionando bases comuns de conhecimento, compartilhamento e colaboração capazes de reforçar o engajamento social, contribuindo para o que afirma Marilena Chauí (2008, p.75): "se podemos pensar numa cidadania cultural, podemos ter certeza de que ela só é possível através de uma cultura da cidadania, viável apenas numa democracia".

Se a sociedade globalmente articulada nos anos 1970, mobilizada por uma perspectiva crítica de enfrentamento ao desenvolvimento sustentável proposto pelas grandes potências, se pautava pelo pensar local e agir global, os anos 1990, a partir das conferências temáticas multilaterais da ONU, introduziram o pensar e agir global. Atualmente, no entanto, os distintos grupos sociais que se movem por projetos comuns em prol da justiça social afirmam modos de pensar e agir global, mas com os pés no local, até quando em iniciativas que ocupam espaços de moradia ou de atuação cultural nos distintos territórios. Mesmo que se articulando a partir de uma 
plataforma digital comum e integrada em níveis regionais e globais, o movimento de direitos humanos assume a Comunicação também como atividade-fim componente de suas lutas, não apenas como ferramenta ou atividade-meio de suas ações.

Assim, uma possível releitura contemporânea do Artigo 19 da Declaração Universal dos Direitos Humanos, referente ao direito à liberdade de expressão, poderia levar em consideração a seguinte formulação: toda pessoa humana tem direito a processos comunicacionais que contemplem a liberdade de expressão e de imprensa, o direito à informação, o direito de se comunicar, bem como a meios democráticos de comunicação que lhes garantam acesso, à posse, à gestão, à produção, à diversidade cultural e ao compartilhamento solidário do conhecimento.

Compreende-se a Comunicação, portanto, como um direito humano fundamental componente determinante e comum de vários setores sociais, relacionado diretamente à construção de identidades e à produção de sentido nas relações cotidianas, capaz de contribuir para o incremento da qualidade nesses diferentes contextos e a própria valorização de outros direitos humanos fundamentais.

Essa definição de trabalho, ao mesmo tempo em que aproxima a Comunicação de outros direitos, fundamenta a necessidade de recompor outras bases para seu aprendizado e processo formativo, bem como sua estruturação profissional. 0 debate sobre Políticas de Comunicação no meio acadêmico ainda é limitado e periférico dentro do próprio campo da Comunicação, a despeito de raras e honrosas exceções.

Ancorada na formulação de políticas públicas para o setor, tal proposta defende e afirma a importância dos territórios de atuação social que se apropriam dos meios e veículos de comunicação em prol da elaboração de práticas democráticas, promovendo a gestão de processos comunicacionais em espaços como escolas, centros de saúde, centros culturais, entre outros, que incentivem não apenas a apropriação de tecnologias de informação e comunicação, como a produção de narrativas capazes de construir aquilo que Martín-Barbero (2004, p. 309) propôs como políticas culturais alternativas de Comunicação, circunscrita na "ativação da competência cultural das pessoas, socialização da experiência criativa e no reconhecimento de diferenças e afirmação de identidades".

Cabe lembrar, no entanto, que esta atuação não se exerce, muito menos se consolida, com a atuação política capaz de viabilizar garantias regulatórias e de viabilidade das políticas para o setor. Em outras palavras, não basta apenas a mobilização política capaz de garantir leis mais democráticas. E justamente por tratarse de área sensível, delicada e suscetível de incômodos às classes dominantes, a garantia da afirmação de direitos conquistados é extremamente volátil, como estão experimentando distintos países na América Latina.

Ao ser colocada como coadjuvante ou mesmo como um tema tabu em determinados contextos políticos locais/nacionais, a Comunicação deixa de ser compreendida como tema prioritário / necessário para a desprendimento de energias por parte de políticos, partidos, movimentos e mesmo coletivos, estes mais diretamente relacionados à viabilidade de suas ações. Por outro lado, ao serem tornados visíveis temas como o combate às opressões e a afirmação de territórios periféricos, a temática da comunicação se dilui para condições identitárias, que deslocam o foco na formulação de políticas públicas para a área de Comunicação, mesmo que a compreendam como processo constitutivo de suas identidades e narrativas, para além da dimensão meramente instrumental. 
Assim, cabe compreender as distintas realidades político-regulatórias na área de Comunicação entre os distintos países da América Latina, com especial interesse na fragilidade do investimento por parte do Estado na consolidação de um sistema democrático, dotado de iniciativas público-estatais e sócio-comunitárias fortes, para além do já conhecido domínio das iniciativas privadas no setor. Essa tarefa vem sendo trabalhada através do ProLocal (http://www.prolocal.uff.br), um portal implementado para disponibilizar informação necessária para o fomento de pesquisas nos meios acadêmico e social, possibilitando identificar demandas a serem implementadas na forma de políticas públicas a serem definidas e / ou implementadas pelos distintos países.

Essa plataforma busca disponibilizar informações relacionadas ao projeto, oferecendo um amplo mapeamento a respeito das políticas locais de Comunicação na América Latina, especialmente a Comunicação Comunitária. Compreende a investigação qualitativa das estruturas de Estado para lidar com o setor, das legislações de referência e principais atores sociais que se mobilizam pela formulação, aprovação e implementação de suas políticas.

Os conteúdos disponibilizados fazem do portal uma plataforma de articulação acadêmica e social, pautada na ideia de que setores de comunicação atuem como um conjunto interligado, que atue em complementaridade e na promoção de interfaces, na medida em que é por essas distintas vias que circulam os conteúdos que se pretendem plurais e diversos, democráticos e inclusivos, capazes de proporcionar um sistema de comunicação que se paute por novas visões em debate na sociedade, que valorize o conjunto dos direitos humanos em relação ao qual a comunicação está inserida, articulando demandas específicas do movimento pela democratização da comunicação e de movimentos gerais.

Coloca-se, portanto, como desafio para a afirmação do papel do Estado e seus poderes constitutivos, bem como para partidos e organizações mais distintas da sociedade, a visibilidade dos distintos setores na formulação de legislações nacionais relacionadas à comunicação, bem como a implementação, a fiscalização e mesmo o fomento e a capacitação de iniciativas capazes de incrementar a participação e a cidadania através de produtos e processos que reflitam a diversidade cultural dos povos latino-americanos.

\section{CONCLUSÃO}

A proposta deste trabalho foi a de apresentar as imbricadas relações entre Comunicação e Cultura como capazes de enfrentar a ofensiva neoliberal e neoconservadora que atinge não apenas a América Latina, como vários países em todo o mundo. Tal ofensiva constitui-se a partir de uma agenda liberal na economia, mas conservadora nos costumes, articulada globalmente, mas se colocando abertamente contrária a ideias como nação e o que compreendem como globalismo, associando-os a um papel que vem sendo conduzido pela ONU na afirmação de direitos humanos incompatíveis com seus valores.

Embora as forças conservadoras tenham se expandido em organizações políticas e sociais articuladas em todo mundo, tendo conquistado espaços políticos, intervindo em organismos multilaterais e promovendo eventos de mobilização global, a afirmação de áreas como Comunicação e Cultura precisa ser trabalhada em articulação com outros direitos humanos, visando fortalecer propostas capazes de oferecer ferramentas e narrativas para a afirmação de políticas de combate às 
opressões, à corrupção e à visibilidade de territórios comprometidos com a afirmação da justiça social e de sociedades democráticas.

A dimensão política desses processos precisa ser trabalhada nos âmbitos acadêmico e social, compreendendo a formulação e a implementação de pesquisas e iniciativas capazes de proporcionar ferramentas qualificadas para a capacitação, o debate e a atuação de pessoas capazes de promover produtos e processos que afirmem a Comunicação como direito humano, bem como reforcem a pluralidade e a diversidade cultural no âmbito dos distintos territórios que compõem a multifacetada América Latina.

Recompor o cenário de aviltamento aos direitos humanos colocado em marcha por governos neoconservadores no continente é uma tarefa árdua, principalmente pelo deteriorado tecido social que segue oferecendo resistência, a despeito de sucessivas perdas trabalhistas e de qualidade de vida nos mais diversos setores. No entanto, justo por isso e em função disso é que compreende-se não apenas possível, mas necessária e determinante a devida visibilidade para as áreas de Comunicação e Cultura na interlocução com contribuições capazes de restituir sentidos democráticos e cidadãos em prol da vida comum.

Artigo recebido em 28/12/2019 e aprovado em 23/04/2020.

\section{REFERÊNCIAS}

AIRES, Janaine, SANTOS, Suzy. Sempre foi pela família: mídias e políticas no Brasil. Rio de Janeiro: Mauad X, 2017.

BARKER, Chris. Televisión, globalización y identidades culturales. Paidós: Barcelona, 2003.

BASES de um programa para a democratização da Comunicação no Brasil. FNDC. 1994. Disponível em: <http://www.fndc.org.br/doc_historico/data/programa.doc>. Acesso em: 13/12/2004.

BITELLI, Marcos Alberto S. O direito da comunicação e da comunicação social. São Paulo: Editora Revista dos Tribunais, 2004.

BOLAÑO, César, BRITTOS, Valério, GOLIN, Cida. Economia da Arte e da Cultura. São Paulo: Itaú Cultural, 2010.

BRASIL. Constituição da República Federativa do Brasil de 1988. Planalto. Disponível em <http://www.planalto.gov.br/ccivil_03/constituicao/constituicao.htm>. Acesso em: 02 mai. 2014.

BRASIL. Ministério das Comunicações. Lei $n^{\circ}$ 11.652, de 07 de abril de 2008. Diário Oficial [da] República Federativa do Brasil, Poder Legislativo, Brasília, DF, 08 abr 2008. Seção 1, p.01. Disponível em: <http://www.planalto.gov.br/ccivil_03/_ato20072010/2008/lei//11652.htm>. Planalto. Acesso em: 02 mai. 2014.

BRASIL. Ministério das Comunicações. Medida Provisória no 398, de 10 de outubro de 2007. Disponível em: <http://www.planalto.gov.br/ccivil_03/_Ato20072010/2007/Mpv/398.htm>. Planalto. Acesso em: 02 mai. 2020.

CABALLERO, Francisco Sierra and GRAVANTE, Tommaso. Digital Media Practices and Social Movements. A Theoretical Framework from Latin America. In CABALLERO, Francisco Sierra and GRAVANTE, Tommaso (orgs). Networks, movements and 
technopolitics in Latin America. Critical analysis and current changes. United Kingdom, Palgrave, 2018.

CABRAL, Eula D.T. Concentração da Mídia no Brasil: Estudo dos Conglomerados de Radiodifusão e Telecomunicações. Rio de Janeiro: Pesquisa de Pós-Doutorado. Universidade do Estado do Rio de Janeiro, 2015a.

CABRAL, Eula D.T. Políticas de comunicação e de cultura acessíveis à sociedade: $O$ projeto EPCC. In: CABRAL, Eula D.T. Desafios das políticas de comunicação. São Cristóvão: ULEPICC-Brasil , 2019. Disponível em <https://e4e47cdb-2958-4c86-b97530657abd4737.filesusr.com/ugd/ad71bb_5c9528d6od114a73bec3c5aeb7985f28.pdf>. Acesso em 10 dez.2019.

CABRAL, Adilson. V. Centro de mídia independente: os primórdios do ativismo digital no Brasil. Curitiba: Appris, 2019.

CABRAL, Adilson V. Nossa TV digital: o cenário internacional da apropriação social da digitalização da TV. Rio de Janeiro: E-papers, 2015.

CABRAL, Adilson V. Regulamentação democrática da radiodifusão comunitária. In: CABRAL, Eula D.T. Desafios das políticas de comunicação. São Cristóvão: ULEPICCBrasil , 2019. Disponível em <https://e4e47cdb-2958-4c86-b97530657abd4737.filesusr.com/ugd/ad71bb_5c9528d6od114a73bec3c5aeb7985f28.pdf>. Acesso em 10 dez.2019.

CALABRE, L. História das políticas culturais na América Latina: um estudo comparativo de Brasil, Argentina, México e Colômbia. Revista Escritos, Ano 7, № 7. Rio de Janeiro: FCRB, 2013, p. 323-345.

CANCLINI, Néstor Garcia (Org.). Políticas Culturales en América Latina. Buenos Aires: Grijalbo, 1987.

CARVALHO, Marcella S. Cultura, Constituição e direitos culturais. IN: CUNHA FILHO, Francisco Humberto, BOTELHO, Isaura, SEVERINO, José Roberto. Direitos culturais. Salvador: EDUFBA, 2018.

CHAUÍ, Marilena. Cultura e democracia. In: Crítica y emancipación: Revista latinoamericana de Ciencias Sociales. Ano. 1 (jun. 2008- ). Buenos Aires: CLACSO, $2008 . \quad$ Disponível em <http://bibliotecavirtual.clacso.org.ar/ar/libros/secret/CyE/cye3Sza.pdf>. Acesso em 7 fev.2018.

FEBBRO, Eduardo. Todos se inspiran en Gramsci. Publicado em Página|12, de 02 de abril de 2018. Disponível em https://www.pagina12.com.ar/105357-todos-se-inspiranen-gramsci. Acesso em 02/05/2020.

HOLLOWAY, John. Mudar o mundo sem tomar o poder. São Paulo: Viramundo, 2003.

LEAL FILHO, Laurindo. A TV sob controle: a resposta da sociedade ao poder da televisão. São Paulo: Summus, 2006.

LIMA, Venício A de. Política de comunicações: um balanço dos governos Lula (20032010). São Paulo: Publisher Brasil, 2012.

LINDGREN-ALVES, José Augusto. É preciso salvar os direitos humanos. São Paulo: Perspectiva, 2018.

MARTÍN-BARBERO, Jesus. Ofício do cartógrafo. Travessias Latino-Americanas da Comunicação na Cultura. São Paulo, Loyola, 2004. 
MELO, José Marques de e SATHLER, Luciano. Direitos à comunicação na sociedade da informação (orgs). São Bernardo do Campo: Metodista, 2005.

MORAES, Dênis de. Crítica da Mídia \& Hegemonia Cultural. RJ: Mauad X, Faperj, 2016

A batalha da mídia: governos progressistas e políticas de comunicação na América Latina e outros ensaios. Rio de Janeiro: Pão e Rosas, 2009.

MOREIRA, Gislene. É legal? A regulação da Comunicação Comunitária na esquerda latino-americana. In. Intercom, Rev. Bras. Ciências da Comunicação vol.36 no.1 São Paulo Jan./June 2013. Disponível em <http://dx.doi.org/10.1590/S180958442013000100011>. Acesso em 09/01/2015.

MOSCO, Vincent. Becoming digital: toward a Post-Internet Society. Bingley, Emerald, 2017.

MOUNK, Yascha. $O$ povo contra a democracia. Por que nossa liberdade corre perigo e como salvá-la? Rio de Janeiro, Companhia das Letras, 2018.

ONU. Assembleia Geral das Nações Unidas. Declaração Universal dos Direitos Humanos. $1948 . \quad$ Disponível em http://www.onubrasil.org.br/documentos_direitoshumanos.php. Acesso em 19/10/2019.

PEREIRA JUNIOR, Luiz Costa. A vida com a TV: o poder da televisão no cotidiano. 3 a. Ed. São Paulo: Editora Senac São Paulo, 2002.

PIERANTI, Octávio P.O Estado e as comunicações no Brasil: construção e reconstrução da Administração Pública. Brasília-DF: Abras/Lecotec, 2011.

RAMOS, Murilo César. Às Margens da Estrada do Futuro: comunicações, políticas e tecnologia. Brasília, EDUnB, 2000. Livro eletrônico Disponível em: http://www.unb.br/fac/publicacoes/murilo/ Acesso em: 12/12/2019

SÁEZ BAEZA, Chiara. Tercer sector de la comunicación, Teoría y praxis de la televisión alternativa. Tese de doutorado. Publicado em 2008. Disponível em <https://ddd.uab.cat/pub/tesis/2008/tdx-1021109-003052/csb1de2.pdf>. Acesso en 02/05/2020.

STEINBERGER, Margarethe. Para uma Economia Política das Representações Culturais na América Latina. IN HAUSSEN, Doris F, BRITTOS, Valério. Economia Política, Comunicação e Cultura: aportes teóricos e temas emergentes na agenda política brasileira. Porto Alegre: EDIPUCRS, 2009.

UNESCO. Um mundo e muitas vozes: comunicação e informação na nossa época. Comissão internacional para o estudo dos problemas de comunicação. Rio de Janeiro: FGV, 1983.

WOLFF, Michael. Televisão é a nova televisão: o triunfo da velha mídia na era digital. SP: Globo, 2015. 